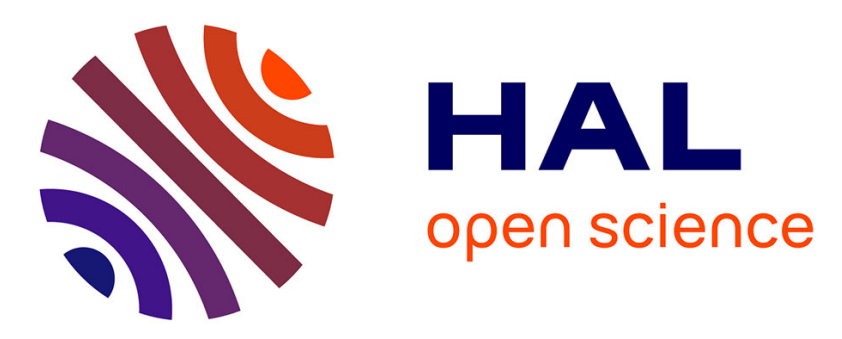

\title{
Monopolar-probe monitoring during spinal surgery with expandable prosthetic ribs
}

\author{
Constantin Gomes, Mathieu Kuchenbuch, Gregory Lucas, Paul Sauleau, \\ Philippe Violas
}

\section{- To cite this version:}

Constantin Gomes, Mathieu Kuchenbuch, Gregory Lucas, Paul Sauleau, Philippe Violas. Monopolarprobe monitoring during spinal surgery with expandable prosthetic ribs. Proccedings of SOO Annual Meeting, Lorient / Travaux de la Société d'Orthopédie et de Traumatologie de l'Ouest, Réunion de Lorient, Jun 2014, Lorient, France. pp.S7-S11, 10.1016/j.rcot.2015.03.002 . hal-01154230

\section{HAL Id: hal-01154230 \\ https://hal-univ-rennes1.archives-ouvertes.fr/hal-01154230}

Submitted on 10 Sep 2015

HAL is a multi-disciplinary open access archive for the deposit and dissemination of scientific research documents, whether they are published or not. The documents may come from teaching and research institutions in France or abroad, or from public or private research centers.
L'archive ouverte pluridisciplinaire HAL, est destinée au dépôt et à la diffusion de documents scientifiques de niveau recherche, publiés ou non, émanant des établissements d'enseignement et de recherche français ou étrangers, des laboratoires publics ou privés. 


\title{
Monopolar-probe monitoring during spinal surgery with expandable prosthetic ribs
}

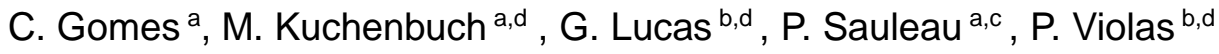

\author{
a Service de neurophysiologie, CHU de Rennes, 35033 Rennes, France \\ b Service de chirurgie orthopédique pédiatrique, $\mathrm{CHU}$ de Rennes, 35033 Rennes, France \\ c Inserm, EA 4712, 35043 Rennes, France \\ d Université Rennes 1, 35043 Rennes, France
}




\section{Abstract :}

Background: Intraoperative monitoring (IOM) has been proven to decrease the risk of neurological injury during scoliosis surgery. The vertical expandable prosthetic titanium rib (VEPTR) is a device that allows spinal growth. However, injuries to the spinal cord and brachial plexus have been reported after VEPTR implantation in 2 and $5 \%$ of patients, respectively. Simultaneous monitoring of these two structures requires the use of multiple time-consuming and complex methods that are ill-suited to the requirements of paediatric surgery, particularly when repeated VEPTR lengthening procedures are needed. We developed a monopolar stimulation method derived from Owen's monitoring technique. This method is easy to implement, requires only widely available equipment, and allows concomitant monitoring of the spinal cord and brachial plexus. The primary objective of this study was to assess the reliability of our technique for brachial plexus monitoring by comparing the stability of neurogenic mixed evoked potentials (NMEPs) at the upper and lower limbs.

Hypothesis: We hypothesised that the coefficients of variation (CVs) of NMEPs were the same at the upper and lower limbs.

Material and methods: Twelve VEPTR procedures performed in 6 patients between 1st January 2012 and 1st September 2014 were monitored using a monopolar stimulating probe. NMEPs were recorded simultaneously at the upper and lower limbs, at intervals of $150 \mathrm{~s}$. The recording sites were the elbow over the ulnar nerve and the popliteal fossa near the sciatic nerve. Wilcoxon's test for paired data was used to compare CVs of the upper and lower limb NMEPs on the same side.

Results: Mean CV of NMEP amplitude at the lower limbs was $16.34 \%$ on the right and $16.67 \%$ on the left; corresponding values for the upper limbs were 18.30 and $19.75 \%$, respectively. Mean CVs of NMEP latencies at the lower limbs were $1.31 \%$ on the right and $1.19 \%$ on the left; corresponding values for the upper limbs were 1.96 and $1.73 \%$. The risk of type I error for a significant difference between the upper and lower limbs was 0.5843 on the right and 0.7312 on the left for NMEP amplitudes and 0.7618 on the right and 0.4987 on the left for NMEP latencies.

Conclusion: Using an epidural active electrode and a sternal return electrode allows simultaneous stimulation of the cervical spinal cord and brachial plexus roots. The NMEPs thus obtained are as stable (reliable) at the upper limbs as at the lower limbs. This easy-toimplement method allows simultaneous monitoring of the upper and lower limbs. It seems well suited to VEPTR procedures.

Level of evidence: IV, retrospective single-centre non-randomised study.

Keywords : Monitoring, Intraoperative, Scoliosis, Paediatric patients, Evoked potentials, Motor 


\section{Introduction}

The vertical expandable prosthetic titanium rib (VEPTR) has a well-established role in spinal surgery for growing children who have thoracic insufficiency syndrome with spinal deformities or multiple fused ribs [1]. Thoracic outlet syndrome and spinal cord compression are the two main complications reported after VEPTR. implantation. The brachial plexus may be injured either directly or by compression between the rib cage and the clavicle or proximal humerus. Somatosensory evoked potentials (SEPs), motor evoked potentials elicited by transcranial electrical stimulation (tcMEPs), and neurogenic mixed evoked potentials (NMEPs) are the most widely used parameters for assessing the somatosensory and motor pathways of the spinal cord. Intraoperative monitoring (IOM) of the brachial plexus usually relies on SEPs; tcMEPs; or continuous, spontaneous or stimulated electromyography [2-4]. Simultaneous IOM of the spinal cord and brachial plexus requires a combination of techniques whose time-consuming and complex implementation is ill-suited to the conditions of surgery and anaesthesia in young children, particularly during revision surgery to provide further lengthening. We describe a method derived from the technique described by Owen et al. [5]. Direct stimulation is applied at two sites, one at the cervical spinal cord and the other at the brachial plexus roots, to allow simultaneous IOM of these two structures. We developed a monopolar device that delivers low-level current to the brachial plexus roots, thus allowing the recording of upper limb NMEPs with only minimal electrical artefacts. Here, our primary objective was to assess the reliability of this monopolar stimulation method for brachial plexus IOM.

\section{Material and methods}

IOM with monopolar-probe monitoring was used for 12 procedures performed in 6 patients between 1st January 2012 and 1st September 2014. We use the Keypoint ${ }^{\circledR} 4.2$ System (Medtronic, Minneapolis, MN, USA), a commercially available IOM device that complies with the European Union standards. The active electrode delivers electrical stimulations no greater than $100 \mathrm{~mA}$ in intensity. The only differences with the conventional IOM method were the type of electrode and position of the return electrode. Whereas conventional epidural stimulation relies on a pair of needle-electrodes, we used a single epidural needleelectrode and a sternal grounding pad. Before the patient was turned in the prone position on the operating table, a wide conductive adhesive pad electrode was applied on the sternal manubrium and connected to the return electrode of the stimulating device. We used 3MTM Series 9160 electrodes (3M Healthcare, St Paul, MN, USA), which usually serve as grounding pads for electric scalpels. Before performing the incision, the surgeon inserted the epidural needle-electrode at C7-T1 down to the ligamentum flavum and connected it to the stimulator. NMEP quality was assessed before starting the surgical procedure. NMEPs were recorded via pairs of subcutaneous electrodes inserted on each side of the patient, in the popliteal fossa near the sciatic nerve at the lower limbs and in the epicondylar groove of the elbow near the ulnar nerve at the upper limbs. Each NMEP was computed as the mean of 50 stimulations at $3.7 \mathrm{~Hz}$ with a 1 -ms long rectangular current on a $30-$ to $3000-\mathrm{Hz}$ bandpass. Mean current intensity producing a supramaximal response was 30 to $50 \mathrm{~mA}$ at the lower limbs and 10 to $30 \mathrm{~mA}$ at the upper limbs. NMEP amplitude (difference between the positive and negative peaks) and latency were recorded at 150-s intervals, first at the upper limbs and second at the lower limbs with no time delay to minimise response variations related to surgical manipulations. All patients received prophylactic antibiotic therapy with cefazoline, together with tranexamic acid to decrease the bleeding risk. Heart 
rate was recorded continuously via pulse oximeter photoplethysmography, as electrical stimulation induces artefacts in electrocardiogram recordings. Also recorded continuously throughout surgery were arterial oxygen saturation ( $\mathrm{SaO} 2)$, blood pressure, and respiratory rate. General anaesthesia was induced with propofol and remifentanil then maintained via inhalation of the halogenated ether sevoflurane in a minimal alveolar concentration (MAC) of 1 or 2 , with a mixture of $60 \%$ nitrous oxide and $40 \%$ oxygen. Neuromuscular blockade was maintained using cisatracurium (1 mg/kg/h). Analgesia was achieved by combining epidural morphine $(10 \square \mathrm{g} / \mathrm{kg} / \mathrm{d}$ ) and a continuous infusion of remifentanil $(0.1-0.2 \square \mathrm{g} \cdot \mathrm{kg}-1 \cdot \mathrm{min}-1)$. Halogenated ether inhalation and neuromuscular blockade were not used in patients with myopathy. Magnetic resonance imaging of the spinal cord was performed routinely to look for spinal cord birth defects. Pre-operatively, tcMEPs and lower limb SEPs were analysed to check that IOM would be feasible.

\section{Statistical analysis}

Pearson's coefficient of variation (CV) is defined as the ratio of the standard deviation (SD) over the mean $(\mathrm{M})$ of a random variable: $\mathrm{CV}=\mathrm{SD} / \mathrm{M}$. This dimensionless parameter serves to compare the dispersion of variables having different physical dimensions or different value scales. The CV is used in quality-control procedures in the industry and in analysis laboratories, as well as in cardiac physiology to assess $R-R$ interval variability. Kim et al. [6] suggested using the CV to compare the stability of MEPs recorded with various levels of neuromuscular blockade. To evaluate the stability of upper limb NMEPs obtained using our monopolar IOM method, we compared NMEPs at the upper and lower limbs. The reliability of lower limb NMEPs for spinal cord IOM is firmly established. Given the lack of evidence that NMEPs are normally distributed [7-9], we chose the non-parametric Wilcoxon's test for paired data to compare same side upper limb and lower limb NMEPs.

\section{Results}

Mean patient age was 7.2 years (range, 6.1-7.9 years) at first VEPTR implantation. The male-to-female ratio was $0.77 / 1$. In addition to congenital spinal and rib defects, many patients had congenital cardiac and neurological abnormalities (Table 1). Mean CVs were about $15 \%$ for NMEP amplitude and $1 \%$ for NMEP latency. Wilcoxon's test for paired data showed no significant differences for NEMPs at the upper versus lower limbs (Tables 2 and 3). NMEP amplitude at the right upper limb dropped sharply in 1 patient. An alert was issued, the threshold being a $40 \%$ amplitude decrease compared to the response recorded at the start of surgery. There was a marked difference between the right and left sides, ruling out defective stimulation (often due to needle-electrode displacement during surgical manipulations). Compression of the brachial plexus was therefore suspected. Lifting the distraction was followed by full NMEP amplitude recovery (Figs. 1 and 2).

\section{Discussion}

To our knowledge, this study provides the first evidence that simultaneous IOM of the brachial plexuses and spinal cord can be achieved using a single stimulation site. This last point considerably simplifies the IOM procedure. Comparisons of CV values established that stability was similar for the lower limb NMEPs recorded using the conventional spinal cord monitoring method and the upper limb NMEPs recorded using our novel monopolar method. Our monopolar stimulator has a single active needle-electrode, which the surgeon inserts at 
C7-T1 down to the ligamentum flavum, and a grounding pad, which is applied to the sternum

before the patient is positioned on the operating table. This 'epidural needle-sternal grounding pad' set-up allows deep stimulation of both the spinal cord and the ventral and dorsal brachial plexus roots, which is difficult to achieve using the conventional 'dual epidural needle set-up'. The risk of brachial plexus and spinal cord injury during VEPTR implantation is now firmly established. In a US multicentre prospective study of 1736 VEPTR procedures (327 primary device implantations, 224 device exchanges, and 1185 device lengthenings) in 299 children, Skaggs et al. identified 8 patients with neurological injuries ( 5 after primary implantation and 3 after device exchange), of whom six had upper limb deficits, including 1 with persistent symptoms after 4 years [10]. Positional nerve injury can occur during a variety of surgical procedures. Their frequency has been estimated at $0.14 \%$, with $38 \%$ of cases involving the brachial plexus [11]. They are most common after spinal or heart surgery. Brachial plexus injury is more common when the patient is in the prone position, particularly with the arms

abducted at 90 ० $[12,13]$. Obesity, diabetes mellitus, and male gender are well-established risk factors. In a retrospective study of 434 procedures, Labrom et al. [14] identified $6.2 \%$ of cases of intraoperative brachial plexus injury revealed by an at least $30 \%$ decrease in SEPs obtained by ulnar nerve stimulation; 2 cases failed to resolve despite re-positioning of the upper limb, and 1 patient had brachial plexus palsy upon awakening. SEP and tcMEP monitoring are the most widely used methods for VEPTR implantation [14,15]. A drawback of these methods is their sensitivity to anaesthesia, particularly of tcMEPs to inhaled halogenated ethers, which requires specifically designed anaesthesia protocols [16-20]. Furthermore, abnormalities present in addition to the spinal abnormalities, such as cerebral palsy and myopathy, may preclude the use of SEP or tcMEP monitoring. In a prospective study of 103 patients scheduled for spinal surgery and assessed pre-operatively by magnetic stimulation, IOM was not feasible in $33 \%$ of patients without MEPs and in $100 \%$ of patients with neither MEPs nor SEPs pre-operatively [21]. The high-frequency electrical currents needed for tcMEP recording can induce seizures, with a frequency estimated at $0.03 \%$. A few cases of cardiac arrhythmia have been reported. Transcranial electrical stimulation is contraindicated or requires special precautions in patients with epilepsy, cortical brain lesions, a skull flap, intracerebral vascular clips, heart disease, a pacemaker, or any type of implanted bioelectrical device [22,23]. In our study, the absence of a significant difference in CVs for NMEPs at the upper versus the lower limbs may be ascribable to the small sample size and to the use of non-parametric statistical tests.

Advantages of using a single needle-electrode placed outside the surgical field are listed below:

- NMEP quality can be assessed after anaesthesia induction and before creating the incision. This advantage is valuable when preoperative testing is difficult, for instance because of behavioural disorders;

- the device takes up less space in the operating field;

- the risk of inadvertent needle-electrode displacement is decreased and NMEP stability improved;

- there is no risk of defective stimulation due to electrical current-fluid bridging between the return and active electrodes, a problem frequently reported with conventional NMEP recording; 
- responses can be monitored continuously throughout the surgical procedure, particularly during the crucial derotation phase.

The most common drawbacks of our monopolar monitoring method are indicated below:

- percutaneous electrode insertion may prove difficult;

- overweight patients require a needle-electrode that is sufficiently rigid and measures at least $50 \mathrm{~mm}$ in length;

- there may be a need for high stimulation intensities, which generate artefacts on ECG monitoring devices but have no adverse physiological effects;

- the method must be modified in patients with contraindications to neuromuscular blockade, of which myopathy is the most common. In this situation, we monitor the muscle motor potentials, at the abductor digiti minimi for the upper limbs and tibialis anterior at the lower limbs. To ensure patient safety, the surgical procedures must be perfectly coordinated with the muscle contractions produced by the spinal cord stimulations. The frequency of the electrical impulses is decreased to $1 \mathrm{~Hz}$ and the number of impulses to 5 (the signal-to-noise ratio remains good, as the muscle response amplitude is about 1000 times the amplitude of responses recorded at a peripheral nerve). In contrast to tcMEP monitoring, there is no risk of tongue bite injury, since the trigeminal nerve is not stimulated. There is a relative contraindication in patients with pacemakers.

Our novel technique proved safe. Major electrocardiographic artefacts occur, but the sternal grounding pad does not affect the heart rate values recorded by pulse oximeter photoplethysmography. Neither is there any change in blood pressure values. The electrical field generated by our needle-pad set-up is conical, with high-density currents concentrated on the spine at the tip of the cone and low-density currents over the manubrium at its base. The amount of energy delivered by the stimulation is probably less than 10 Joules. Interestingly, low-level electrical currents $(\sim 20 \mathrm{~mA})$ are sufficient to elicit supramaximal responses at the upper limbs. This fact may be ascribable to the anterior-to-posterior direction of the electrical fields and to the proximity of the brachial plexus roots.

\section{Conclusion}

Paediatric spinal surgery requires specific IOM techniques. Our work established that monopolar stimulation allows simultaneous IOM of the upper and lower limbs. The set-up time is considerably shorter than with conventional methods. Thus, our novel technique seems well suited to spinal surgery in young children who require repeated anaesthesia to lengthen the spinal growth system without spinal fusion.

Disclosure of interest : the authors declare that they have no conflicts of interest concerning this article. 
Table 1

General characteristics of the 6 patients.

\begin{tabular}{|l|l|l|l|l|l|}
\hline Patient & $\begin{array}{l}\text { Age at first } \\
\text { implantation } \\
\text { (years) }\end{array}$ & Sex & $\begin{array}{l}\text { Congenital } \\
\text { skeletal defects }\end{array}$ & $\begin{array}{l}\text { Other congenital } \\
\text { defects }\end{array}$ & Cause \\
\hline TV & 4.9 & M & $\begin{array}{l}\text { Spondylocostal } \\
\text { dysostosis }\end{array}$ & & $\begin{array}{l}\text { Jarcho-Lévin } \\
\text { syndrome }\end{array}$ \\
\hline AC & 8.3 & F & $\begin{array}{l}\text { Spondylocostal } \\
\text { dysostosis }+ \\
\text { costal fusion }\end{array}$ & Dextrocardia & $?$ \\
\hline KL & 6.5 & F & $\begin{array}{l}\text { Hemivertebrae }+ \\
\text { costal fusion }\end{array}$ & Atrial septal defect & $?$ \\
\hline LB & 6.0 & M & $\begin{array}{l}\text { Vertebral fusion }+ \\
\text { costal synostosis }\end{array}$ & $\begin{array}{l}\text { Diastematomyelia }+ \\
\text { meningocele }\end{array}$ & $?$ \\
\hline MR & 6.8 & M & & $\begin{array}{l}\text { Congenital } \\
\text { diaphragmatic hernia }\end{array}$ & $\begin{array}{l}\text { delion }+ \\
13 q 14.13 \\
\text { duplication }\end{array}$ \\
\hline LR & 10.9 & F & $\begin{array}{l}\text { Severe spinal } \\
\text { curvature >90 }\end{array}$ & $\begin{array}{l}\text { Cleft lip and palate }+ \\
\text { cerebral ventricle } \\
\text { hypoplasia }\end{array}$ & $?$ \\
\hline
\end{tabular}

Table 2

Mean coefficient of variation for neurogenic mixed evoked potential latencies and comparison of upper and lower limbs using the Wilcoxon's rank sum test.

\begin{tabular}{|l|l|l|l|l|}
\hline Side & Lower limbs (\%) & Upper limbs (\%) & Rank sum & P-value \\
\hline Right & 1.31 & 1.96 & 47 & 0.5843 \\
\hline Left & 1.19 & 1.73 & 56 & 0.7312 \\
\hline
\end{tabular}

Table 3

Mean coefficient of variation for neurogenic mixed evoked potential amplitudes and comparison of upper and lower limbs using the Wilcoxon's rank sum test.

\begin{tabular}{|l|l|l|l|l|}
\hline Side & Lower limbs (\%) & Upper limbs (\%) & Rank sum & P-value \\
\hline Right & 16.34 & 18.30 & 53 & 0.7618 \\
\hline Left & 16.67 & 19.75 & 45 & 0.4987 \\
\hline
\end{tabular}


Fig. 1. Adverse event in the right upper limb during the distraction procedure, with a good then recovered totally after an alert by the neurophysiologist and promoted the surgeon outcome. Neurogenic mixed evoked potential (NMEP) amplitude dropped sharply to lift the distraction applied by the vertical expandable prosthetic titanium rib.

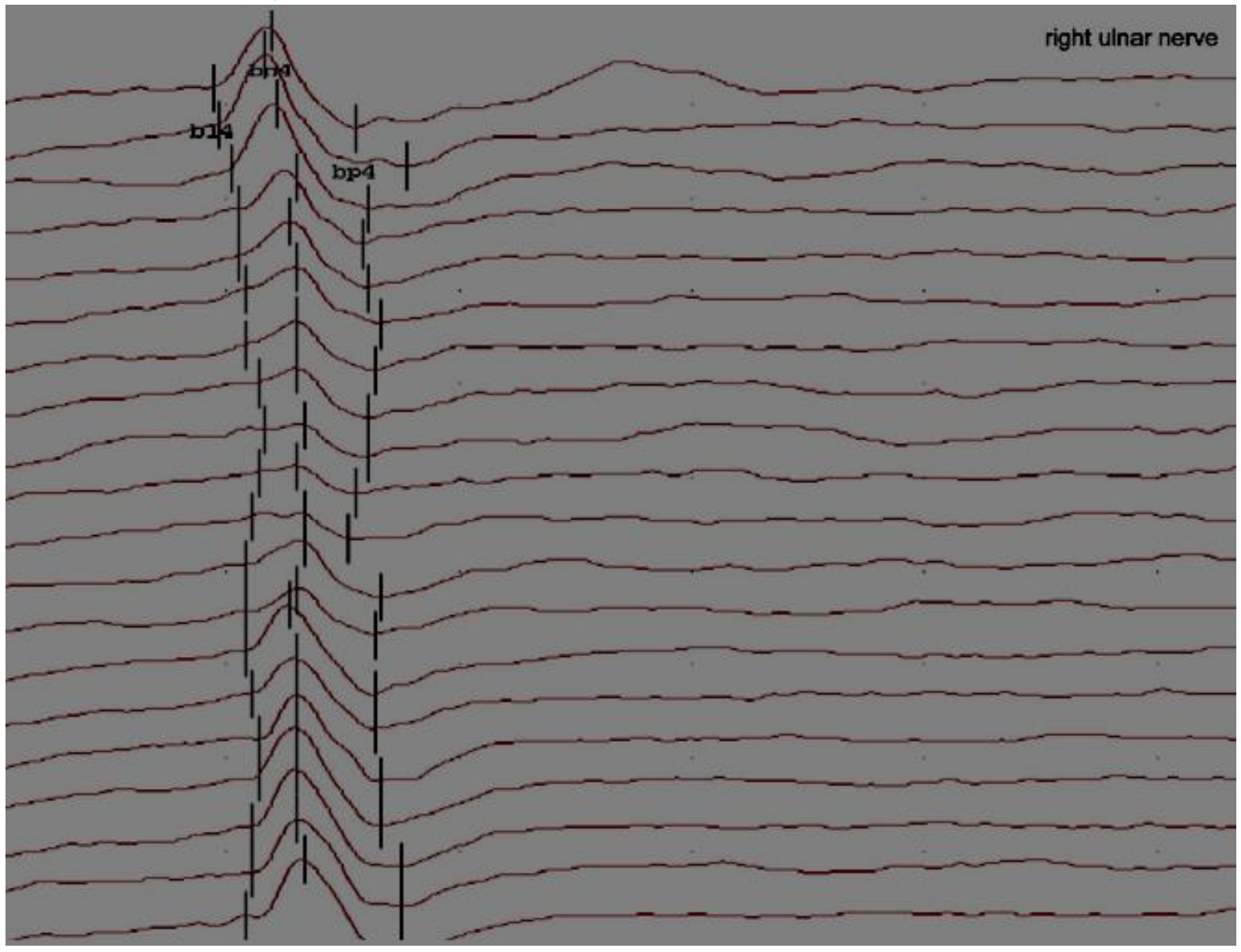


Fig. 2. Graph of the relative neurogenic mixed evoked potentials (NMEP) from the right the right and left sides does not support failure of stimulation (usually due to needle-electrode and left ulnar nerves throughout intraoperative monitoring. The difference between displacement). This difference strongly suggests brachial plexus compression.

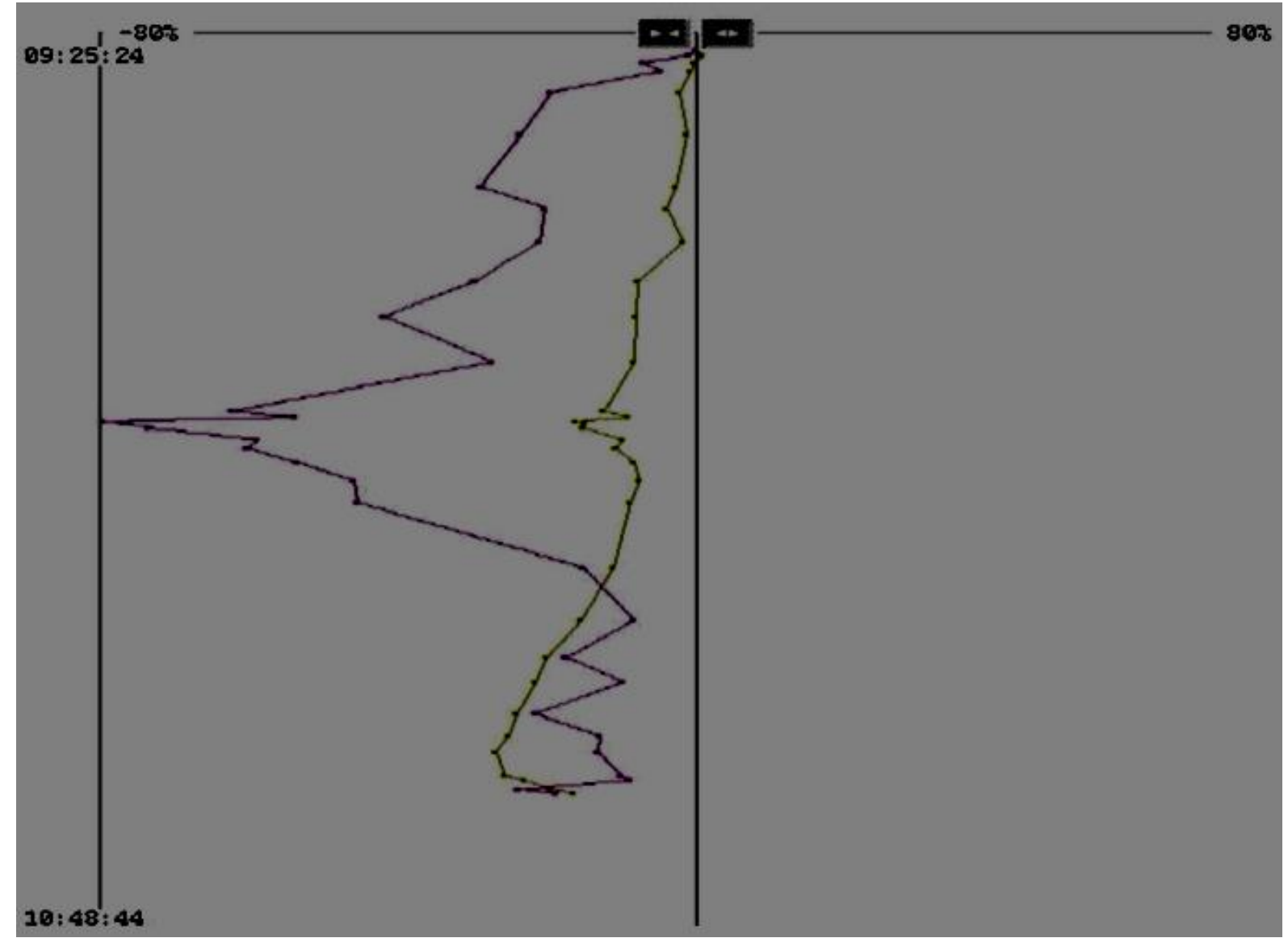




\section{References}

[1] Campbell Jr RM, Smith MD, Mayes TC, Mangos JA, Willey-Courand DB, Kose N, et al. The effect of opening wedge thoracostomy on thoracic insufficiency syndrome associated with fused ribs and congenital scoliosis. J Bone Joint Surg Am 2004;86:1659-74.

[2] Shea KG, Apel PJ, Showalter LD, Bell WL. Somatosensory evoked potential monitoring of the brachial plexus during a Woodward procedure for correction of Sprengel's deformity. Muscle Nerve 2010;41:262-4.

[3] Flynn JM, Sakai DS. Improving safety in spinal deformity surgery: advances in navigation and neurologic monitoring. Eur Spine J 2013;22:131-7.

[4] Gavaret M, Jouve JL, Péréon Y, Accadbled F, André-Obadia N, Azabou E, et al. Intraoperative neurophysiologic monitoring in spine surgery. Developments and state of the art in France in 2011. Orthop Traumatol Surg Res 2013;99:S319-27.

[5] Owen JH, Laschinger J, Bridwell K, Shimon S, Nielsen C, Dunlap J, et al. Sensitivity and specificity of somatosensory and neurogenic-motor evoked potentials in animals and humans. Spine 1988;13:1111-8.

[6] Kim WH, Lee JJ, Lee SM, Park MN, Park SK, Seo DW, et al. Comparison of motor evoked potentials monitoring in response to transcranial electrical stimulation in subjects undergoing neurosurgery with partial vs no neuromuscular block. $\mathrm{Br} \mathrm{J}$ Anaesth 2013;110:567-76.

[7] Abdi H. Coefficient of variation. In: Encyclopedia of research design. Thousand Oaks, CA: Sage Publications, Inc; 2010. p. 169-71.

[8] Toichi M, Sugiura T, Murai T, Sengoku A. A new method of assessing cardiac autonomic function and its comparison with spectral analysis and coefficient of variation of $R-R$ interval. J Auton Nerv Syst 1997;62:79-84.

[9] Shoukri MM, Colak D, Kaya N, Donner A. Comparison of two dependent within subject coefficients of variation to evaluate the reproducibility of measurement devices. BMC Med Res Methodol 2008;8:24.

[10] Skaggs DL, Choi PD, Rice C, Emans J, Song KM, Smith JT, et al. Efficacy of intraoperative neurologic monitoring in surgery involving a vertical expandable prosthetic titanium rib for early-onset spinal deformity. J Bone Joint Surg Am 2009;91:1657-63.

[11] Parks BJ. Postoperative peripheral neuropathies. Surgery 1973;74:348-57.

[12] Schwartz DM, Sestokas AK, Hilibrand AS, Vaccaro AR, Bose B, Li M, et al.

Neurophysiological identification of position-induced neurologic injury during anterior cervical spine surgery. J Clin Monit Comput 2006;20:437-44.

[13] Uribe JS, Kolla J, Omar H, Dakwar E, Abel N, Mangar D, et al. Brachial plexus injury following spinal surgery: a review. J Neurosurg Spine 2010;13:552-8.

[14] Labrom RD, Hoskins M, Reilly CW, Tredwell SJ, Wong PK. Clinical usefulness of somatosensory evoked potentials for detection of brachial plexopathy secondary to malpositioning in scoliosis surgery. Spine 2005;30:2089-93.

[15] Sankar WN, Skaggs DL, Emans JB, Marks DS, Dormans JP, Thompson GH, et al. Neurologic risk in growing rod spine surgery in early-onset scoliosis: is neuromonitoring necessary for all cases? Spine 2009;34:1952-5.

[16] Scheufler K-M, Zentner J. Total intravenous anesthesia for intraoperative monitoring of the motor pathways: an integral view combining clinical and experimental data. J Neurosurg 2002;96:571-9.

[17] Sloan TB, Heyer EJ. Anesthesia for intraoperative neurophysiologic monitoring of the spinal cord. J Clin Neurophysiol 2002;19:430-43. 
[18] Wang AC, Than KD, Etame AB, La Marca F, Park P. Impact of anesthesia on transcranial electric motor evoked potential monitoring during spine surgery: a review of the literature. Neurosurg Focus 2009;27:E7.

[19] Stecker MM. A review of intraoperative monitoring for spinal surgery. Surg Neurol Int 2012;3:S174-87.

[20] Tamkus AA, Rice KS, Kim HL. Differential rates of false-positive findings in transcranial electric motor evoked potential monitoring when using inhalational anesthesia versus total intravenous anesthesia during spine surgeries. Spine J 2014;14:1440-6.

[21] Azabou E, Manel V, Abelin-Genevois K, Andre-Obadia N, Cunin V, Garin C, et al. Predicting intraoperative feasibility of combined TES-mMEP and cSSEP monitoring during scoliosis surgery based on preoperative neurophysiological assessment. Spine $\mathrm{J}$ 2014;14:1214-20.

[22] MacDonald DB. Safety of intraoperative transcranial electrical stimulation motor evoked potential monitoring. J Clin Neurophysiol 2002;19:416-29.

[23] MacDonald DB. Intraoperative motor evoked potential monitoring: overview and update. J Clin Monit Comput 2006;20:347-77. 